\title{
METHODICAL BASES OF THE MODULAR TRAINING TECHNOLOGY WHILE STUDYING GRAMMAR AT NON-LANGUAGE UNIVERSITIES
}

(C) 2017

Lopukhova Yulia Victorovna, doctor of pedagogical sciences,

professor of the Linguistics, Cross-cultural Communication and Russian as a Foreign Language Department

Samara State Technical University (Samara, Russian Federation)

Abstract. The paper considers the need of using a modular training technology while studying grammar in a nonlanguage high school. At the same time the great importance is given to the module structure, which must be organized in such a way that final results have to be focused on individual success of students. It becomes possible because modern modular training technologies change the form of communication between a teacher and a student. Here, education is based on subject-subject communications as one of the main goals of the modular training technology is the development of students' self-education skills. The awareness of educational activity makes it possible to change the role of a teacher from the source of information into counseling and management. The teacher is released from an informational function, delegating this role to the module and some management functions become self-management ones. Students study themselves most of the time getting self-planning, self-organization, selfcontrol, self-assessment skills. Learning content is submitted in self-contained modules, which are at the same time the bank information and the guide. The implementation of modular training technology from the point of the perspective theory of certain skills stage formation supposes that the main educational purpose can be divided into superposes in the frame of individual elements of training modules.

Keywords: modular training technology; module; self-planning; self-organization; self-control; self-assessment; grammar skill; training element; information block; input control; check list; control.

УДК 378.147

\section{ТЕОРЕТИКО-МЕТОДОЛОГИЧЕСКИЕ ОСНОВЫ ОРГАНИЗАЦИИ ПРОЕКТНОЙ ДЕЯТЕЛЬНОСТИ УЧАЩИХСЯ В УЧРЕЖДЕНИЯХ ДЕТСКОГО И ЮНОШЕСКОГО ТВОРЧЕСТВА}

\author{
Михелькевич Валентин Николаевич, доктор технических наук, \\ профессор кафедры психологии и педагогики \\ Самарский государственный технический университет (г. Самара, Российская Федерация) \\ Овчинникова Людмила Павловна, доктор педагогических наук, \\ профессор кафедры философии и истории науки \\ Самарский государственный университет путей сообщения (г. Самара, Российская Федераичия) \\ Лисовская Анна Игоревна, директор \\ Центр детского творчества «Радуга успеха» г.о. Самара (2. Самара, Российская Федерация)
}

\footnotetext{
Аннотация. В статье представлены теоретико-методологические основы организации проектной деятельности учащихся в учреждениях детского и юношеского творчества. На основании проведенного ретроспективного анализа научных публикаций и передового педагогического опыта по проблеме обучения и творческого развития молодежи в системе дополнительного образования, и в частности в центрах детского и юношеского творчества, показано, что доминирующим видом педагогической технологии обучения учащихся моделированию, конструированию и приобщению к самостоятельной и творческой деятельности является проектная технология. Рассматриваются и обосновываются ценности и преимущества проектной технологии по сравнению с известными традиционными и инновационными педагогическими технологиями. Показано, что проектная технология ориентирована на интеграцию, на синтез теоретических знаний учащихся с их непосредственной практической деятельностью, поскольку в процессе выполнения проекта производится не только постановка и решение определенной умственной, творческой задачи, но и ее практическая реализация в виде чертежей, рисунков, программных продуктов, моделей и макетов машин, устройств, роботов, приборов. Показано также, что в процессе выполнения проекта ученик учится и получает навыки выявления социально-технических противоречий и проблем и путей их устранения. Ценность проектной технологии состоит также и в том, что она ориентирована на самостоятельную творческую деятельность учащегося, в результате выполнения которой у него формируются и закрепляются навыки самоорганизации самостоятельной работы. В статье рассматривается типология учебных проектов, используемых в Центре детского и юношеского творчества, а также методика их индивидуального и селективного выбора. Рассматриваются важнейшие классификационные признаки учебных проектов: ведущая модальность учебно-познавательной деятельности проектантов; уровни межпредметной интеграции знаний, необходимых и приобретаемых учащимися в процессе выполнения проекта; субъекты и условия организации проектной деятельности.

Ключевые слова: теоретико-методологические основы организации проектной деятельности; проектная технология; классификационные признаки учебных проектов; учащиеся; дополнительное образование; типология учебных проектов; практическая деятельность; центры детского и юношеского творчества.
} 
Михелькевич В.Н., Овчинникова Л.П., Лисовская А.И.

Анализ научных публикаций и передового педагогического опыта по проблеме обучения и творческого развития молодежи в системе дополнительного образования, и в частности в центрах детского и юношеского творчества, свидетельствует, что доминирующим видом педагогической технологии обучения учащихся моделированию, конструированию и приобщению к самостоятельной познавательной и творческой деятельности является проектная технология [1-3]. Многолетний опыт деятельности Центра детского и юношеского творчества «Радуга успеха» г.о. Самары полностью согласуется с этой глобальной тенденцией доминирующего использования проектной технологии обучения и личностного развития.

Проектная педагогическая технология получила признание и широкое использование во всех сферах и уровнях образования, в том числе дополнительного образования, благодаря ряду своих ценностей и преимуществ по сравнению с другими традиционными и инновационными технологиями. В связи с этим рассмотрим их основные характеристики и обусловленные ими дидактические ценности. Изначально метод проектов получил свое признание и применение в общеобразовательной школе в прагматической педагогике (концептуальные основы которой разработал Д. Дьюи [4]), где стал ведущим методом обучения. Само название «прагматическая педагогика» (pragma - дело, действие) определяет основной принцип обучения - «обучение посредством делания». Основу, стержень проекта составляет целевая установка на решение конкретной проблемы, позволяющая вовлечь каждого обучаемого в активный творческий познавательный процесс. При этом направленность учебно-познавательного процесса должна быть достаточно прагматична, чтобы учащиеся знали, зачем им необходимы те или иные знания, для решения каких жизненно важных проблем они могут быть полезны. Проектная технология обучения ориентирована на интеграцию теоретической и практической деятельности, поскольку в процессе выполнения проекта осуществляется не только постановка и решение определенной умственной задачи, но и ее практическая реализация в виде чертежей, рисунков, программных продуктов, макетов и конструкций различных машин, роботов, приборов. Метод проектов всегда предполагает решение какой-то проблемы. Поэтому некоторые ученые-педагоги называют его «методом проблем» [5].

Учебная проектная деятельность, индивидуальная или групповая, организуется так, чтобы целью познавательных действий учащихся было не просто усвоение нового или углубление освоенного в основной школе содержания учебного материала, а решение определенной проблемы на основе этого содержания, чтобы имело место активное применение приобретенных знаний либо для получения нового знания, либо для получения практического результата на основе полученного знания и чтобы учащиеся четко представляли, как можно использовать усвоенную ими теорию на практике. Весьма существенно, что при выполнении учебного проекта ученик получает навыки выявления проблем (по сути дела, противоречий, возникающих на пути созда- ния какого-то технологического процесса, интеллектуального и материального объекта для удовлетворения потребностей человека), вырабатывает умение поиска путей и средств их устранения или локации, способов усовершенствования известных или создания новых объектов. Метод проектов ориентирован на самостоятельную творческую проектную деятельность учащихся, которая выполняется либо индивидуально, либо группой учащихся под руководством (или с помощью) учителя в течение определенного отрезка времени. В результате этого вида деятельности у них формируются умения и закрепляются навыки организации самостоятельной работы и добывания необходимой информации из библиографических источников, патентных фондов, сети Интернет, самостоятельного принятия решений при рассмотрении многокритериальных оптимизационных задач, технического и графического оформления результатов выполнения работы, презентации своих разработок и ряд других компетенций, требующих проявления личной инициативы и предприимчивости. Д. Дьюи и его последователи пытались организовать не просто активную познавательную деятельность, но и деятельность на основе совместного труда, сотрудничества учащихся в процессе общения, коммуникации. То, что не мог сделать один ученик, в совместной деятельности оказалось вполне достижимым, причем на основе собственных, самостоятельных усилий.

На существование этого педагогического феномена еще в середине XIX в. указывал американский философ и писатель Ральф Эмерсон: «Совместный труд воспламеняет в людях такую ярость свершений, какой они редко могут достичь в одиночку». Поэтому и в современной проектной технологии обучения индивидуальный подход органично сочетается с групповым. По мнению Е.С. Полат, собственно, обучение в сотрудничестве является составной частью метода проектов [6]. Дело в том, что сам по себе этот метод, используемый в отрыве от обучения в сотрудничестве, очень быстро обнаруживает существенные трудности в современной деятельности учащихся. Ведь при работе над проектом (если это не индивидуальный проект) объединяются учащиеся разной степени подготовленности, и очень часто оказывается, что одни ученики готовы к поисковой, исследовательской, творческой деятельности - они обладают достаточным запасом знаний для такой деятельности, а другие абсолютно не готовы и потому могут выполнять лишь роль статистов. Поэтому и возникает педагогическая проблема - подготовить всех учащихся к посильной для каждого, но обязательно активной познавательной деятельности над проектом. Одним из важнейших принципов метода проекта является такая организация учебного процесса, которая бы служила детским интересам сегодняшнего дня. «Детство не есть проходная комната вестибюль, через которую мы пробираемся к существованию взрослого. Это самостоятельная внутренняя комната в хоромах жизни. Это реальный период, изживаемый сам по себе. На него нельзя смотреть как на подготовку к жизненной стадии взрослого», писал В.Х. Килпатрик [7]. Сущность и ценность метода проектов состоит в том, что он позволяет учащимся выбирать деятельность по своим интересам, 
по своим силам, что создает сильную мотивацию познания и способствует зарождению интереса к последующим делам, побуждает учащихся активно использовать имеющиеся и добывать новые знания, вырабатывать умения и навыки решения конкретных проблем. Метод проектов позволяет активно развивать у учащихся основные виды мышления, творческие способности, стремление созидать самому, осознавать себя творцом при работе с «непослушными инструментами» и «неподатливыми материалами», с «умными машинами» и «технологическими системами». В процессе проектирования у учащихся вырабатываются и закрепляются навыки анализа потребительских, экономических, экологических и технологических ситуаций, способность оценивать идеи, исходя из реальных потребностей, материальных возможностей, умения выбирать наиболее технологичный, экономичный, отвечающий требованиям дизайнера способ изготовления объекта проектной деятельности (продукта труда) [8]. Большинство ученых-педагогов считают, что любая учебная проектная деятельность является творческой, и с этим смелым утверждением нельзя не согласиться. Это утверждение исходит из идеи Д. Дьюи, что «сущностью процесса учения является открытие - реальное постоянное воплощение чего-то нового». Обучающийся учится на основе творческого мышления, при этом каждая решенная им задача является творческим актом.

Творческая деятельность учащихся стимулируется созданием атмосферы исследовательской свободы. Поэтому в педагогике прагматизма учитель (ру- ководитель кружка, лаборатории, студии; тьютор) не столько учит, сколько подает мысль, не столько излагает, сколько отвечает на призыв к руководству. Широкий спектр используемых технологий проектов (исследовательские, прикладные, информационные, экологические и т.д.), индивидуальный субъектсубъектный характер взаимодействия учителя и учащихся, самостоятельная работа ученика над проектом по избранной им теме в удобное для него время и в желаемом темпе позволяют осуществлять личностно-ориентированное обучение с учетом индивидуальных способностей и интересов каждого обучаемого. Проектные технологии обучения являются также эффективным дидактическим инструментарием социализации мышления и деятельности учащихся. Это объясняется тем, что изначально учебный проект ориентирован на решение конкретной проблемы, имеющей определенную прагматическую ценность и социальную значимость. Работая над разрешением проблемы, учащийся приобщается к деятельности по обеспечению тех или иных жизненных потребностей общества, многократно и по многим аспектам соприкасается с социальной средой и природой, осознает свое соучастие в социальных процессах.

Важнейшим компонентом организации проектной деятельности учащихся является типология учебных проектов [9]. При большом числе и разнообразии используемых в проектной деятельности Центра детского и юношеского творчества их целесообразно систематизировать и образно представить в виде объемной морфологической матрицы типологий учебных проектов (рис. 1).

\section{Ү. Уровни предметной интеграции знаний}

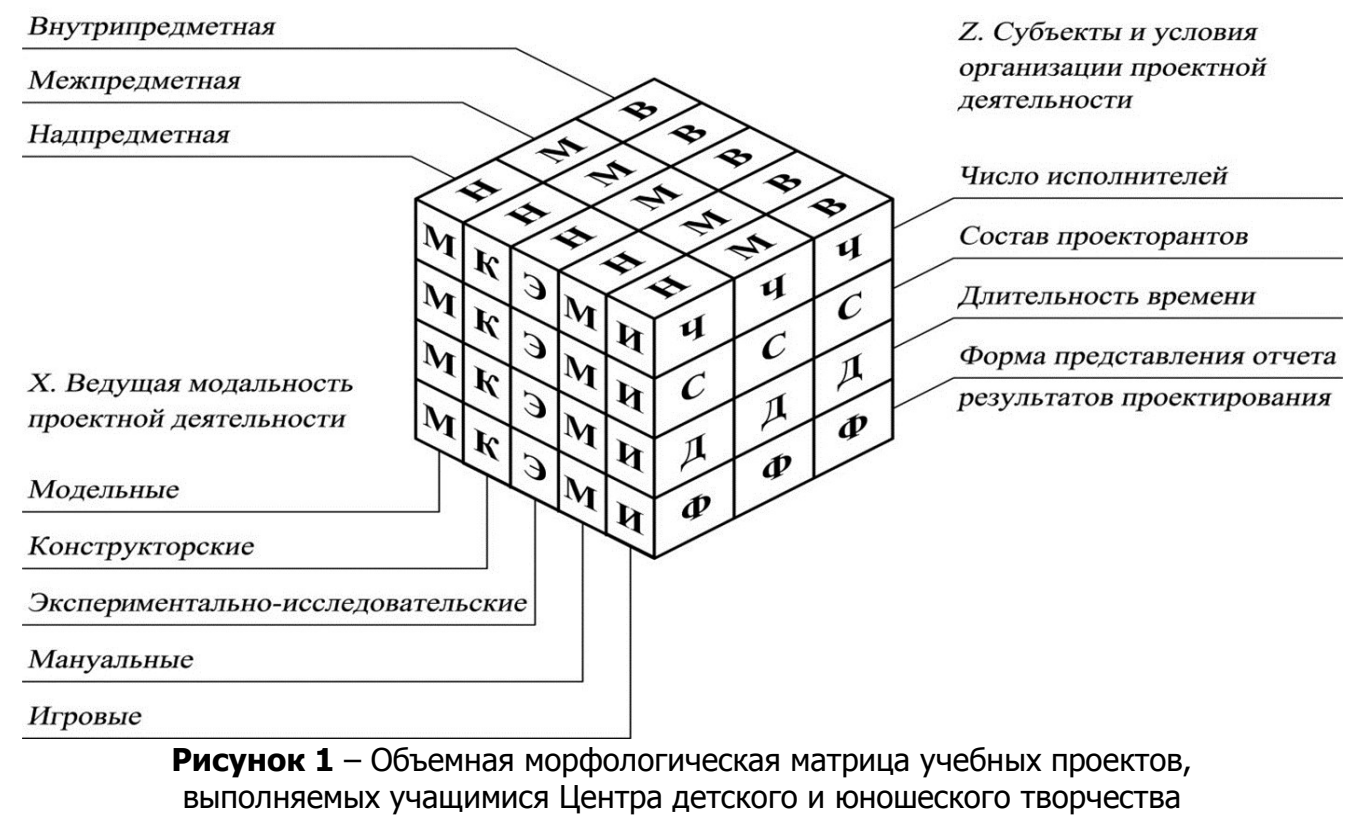

На этом рисунке по оси $\mathrm{X}$ представлены типы проектов, характеризующие их основное содержание и ведущую модальность учебно-познавательной деятельности учащихся; по оси $\mathrm{Z}$ - проекты, характеризующие субъектов, условия и организацию проектной деятельности; а по оси Y - типы проектов с разными уровнями интеграции межпредметных знаний, необходимых и приобретаемых учащимися в процессе их выполнения.
По типу ведущей модальности учебно-познавательной деятельности учащихся проекты подразделяются на:

- модельные - создание разнообразных моделей, машин, роботов, приспособлений, приборов и т.п.;

- конструкторские - разработка проектов и изготовление по ним разнообразных конструкций из дерева, пластика, металла для выставок, для дома, для школы и т.п.; 
Михелькевич В.Н., Овчинникова Л.П., Лисовская А.И.

- экспериментально-исследовательские - проведение исследований физических явлений, информационных процессов в сфере экологической чистоты и безопасности;

- мануальные - выполняются собственными руками учащихся (вязание, вышивание, лепка, чеканка, резьба по дереву и т.п.), их конечный результат представлен в виде каких-то материальных поделок, опытных образцов механизмов [10];

- игровые проекты - используются в основном при обучении учащихся младшего возраста в целях формирования у них смекалки, инициативы и творческого мышления $[11 ; 12]$. При этом в качестве тем могут быть использованы сюжеты сказок народов мира, интеллектуальные и логические игры, компьютерные игры и т.п. Пользуются большим интересом и ролевые игры по истории изобретений и открытий $[13 ; 14]$. В таких проектах композиция игры только намечается и остается открытой до ее завершения. Участники игры принимают на себя роли, обусловленные содержанием и характером проекта. Это могут быть литературные персонажи или выдуманные герои, которые имитируют социальные или деловые ситуации и межличностные отношения.

В ряде случаев учащиеся Центра выполняют и комплексные учебные проекты, в которых в той или иной мере имеет место сочетание выше рассмотренных модальностей. По уровню предметной интеграции знаний, используемых и приобретаемых учащимися в процессе выполнения учебных проектов (координата Y на рис. 1), последние подразделяются на внутрипредметные (монопредметные), межпредметные и надпредметные, в которых не только используются знания, входящие в состав дисциплин учебного плана, но и знания из других областей науки и техники (робототехники, кибернетики, квалиметрии, материаловедения и др.)

Учебные проекты классифицируются также по составу субъектов проектной деятельности и ее организацию (координата $\mathrm{Z}$ на рис. 1):

- по численности и составу участников проекта;

- по длительности времени, отводимого на выполнение проекта;

- по форме представления результатов выполнения.

По количеству участников проекты могут быть индивидуальными или групповыми [15; 16]. В группе проектировщиков (2-3 человека) могут быть учащиеся разного возраста, из разных классов обучения и даже из разных школ.

По длительности времени, отводимого на выполнение проекта, они подразделяются на краткосрочные (1-2 недели), среднесрочные, выполняемые в течение одной четверти учебного года, и долгосрочные, выполняемые в течение полугода или всего учебного года. Выбор этого типа проектов определяется, главным образом, возрастом ученика, его увлеченностью проблемой, целеустремленностью, настойчивостью и прилежанием.

И наконец, немаловажной организационно-методической характеристикой учебных проектов является форма представления результатов проектной деятельности учащихся: описание, рабочие чертежи, макеты моделей, готовые поделки, опытные образцы машин и приборов. В последние годы стало традици- онным представлять результаты проектных разработок в виде компьютерных презентаций, в том числе Power Point версии 03 [17], что при современном уровне подготовки школьников по информатике стало общедоступным для большинства учащихся, занимающихся в Центре детского и юношеского творчества.

Выбор темы учебного проекта производится избирательно и индивидуально для каждого обучающегося в Центре с учетом его возраста и уровня школьного образования, его личностных интересов и наклонностей, его желания работать в одиночку или в группе (интроверт - экстраверт), и других факторов, а также с учетом возможностей и материальнотехнических ограничений учреждения [18; 19].

Процесс проектирования и этапы его организации в обобщенном виде можно представить в виде следующих последовательно реализуемых этапов:

1. Знакомство с целями и задачами учебного проектирования.

2. Выбор темы и жанра учебного проекта, осмысление и формулировка проблемы.

3. Погружение в проблему, конкретизация и уточнение задач.

4. Поиск аналогов и прототипов, генерированных идей по созданию или усовершенствованию проектируемого объекта.

5. Планирование проектных работ в рамках установленного времени.

6. Рабочий, творческий этап: непосредственное выполнение запланированных работ (расчеты, моделирование, экспериментальные исследования, изготовление, монтаж, наладка и т.п.).

7. Обобщение результатов и экспертиз выполненных работ по проекту.

8. Техническое оформление выполненного проекта (отчета, моделей, макетов, подготовка презентационных материалов) [20].

9. Защита/презентация выполненного проекта, выступление на конференции, представление экспоната на выставках разных уровней.

Руководители кружков, студий, лабораторий, учителя ведут непрерывный контроль и творческое сопровождение выполняемых учащимися проектов. Выполняемая работа по проекту оценивается комплексно по трем критериям: по содержанию и социально-дидактической значимости (аргументированное принятие решений, качество и оригинальность изготовленного материального объекта, модели или макета; прагматическая ценность от использования проектной разработки; уровень творчества, проявленного учеником; по качеству оформления проектной документации или изготовленного макета, модели (стиль и язык изложения отчета, объем, полнота и логическая завершенность проектной разработки, внешний вид (дизайн) выполненной работы) и по успешности презентации проекта (умение выступать и излагать перед аудиторией свои мысли, аргументированность подходов к изложению результатов работы, глубина знаний по рассматриваемой проблеме, мобильность при ответах на вопросы оппонентов). Завершенные творческие проекты обычно публично защищаются и оцениваются жюри/комиссией, состоящей из нескольких учителей Центра и руководителя проекта. 
Для стимулирования проектной учебно-познавательной деятельности учащихся, кроме высоких оценок, устной похвалы и одобрения, используются такие формы морального поощрения, как награждение грамотами, дипломами, призами, как представление выполненных творческих разработок на районных и городских выставках, на научно-технических молодежных конференциях и форумах.

\section{СПИСОК ЛИТЕРАТУРЫ:}

1. Селевко Г.К. Энциклопедия образовательных технологий. В 2-х томах. М.: НИИ школьных технологий. Т. 1, 2006. 816 с.; Т. 2, 2006. 816 с.

2. Галицков С.Я., Михелькевич В.Н. Проектирование: технологии обучения. Самара: Издательство СГАСУ, 2014. 104 c.

3. Михелькевич В.Н., Охтя Н.В. «Метод проектов» и его использование в средней общеобразовательной и высшей инженерной школах: учебное пособие. Самара: Изд-во СГТУ, 2004. 48 с.

4. Современные образовательные технологии: уч. пособие / под ред. Н.В. Бордовской. М.: КНОРУС, 2013. $432 \mathrm{c}$.

5. Михелькевич В.Н., Нестеренко В.М., Кравцов П.Г. Инновационные педагогические технологии: учебное пособие. Самара: Изд-во СГТУ, 2004. 91 с.

6. Новые педагогические и информационные технологии в системе образования / под ред. Е.С. Полат. М.: Изд-во Академия, 1999. 246 с.

7. Килпатрик В.Х. Метод проектов. Применение целевой установки в педагогическом процессе. Л.: Изд-во Брокгауз - Ефрон, 1925. 43 с.

8. Овчинникова Л.П. Теория и практика управления самостоятельной работой студентов-заочников: монография. Самара: Изд-во СамГУПС, 2012. 191 с.

9. Бочкарев А.И., Бочкарева Т.С. Социокультурное проектирование инновационной творческой среды: монография. Тольятти: Изд-во ПГУС, 2012. $521 \mathrm{c}$.

10. Петров А.В. Мануальная деятельность как фактор развития личности в исследованиях русских и немецких педагогов - сравнительные системы выс- шего образования и сравнительная педагогика // доклады Межд. конф. Новгород: Изд-во НГУ, 1998. $258 \mathrm{c}$.

11. Борзова В.А., Борзов А.А. Путь к творческому мышлению. Энциклопедия Самара: ООО ПД «ДСМ», $2016.320 \mathrm{c}$.

12. Медяник Г.Д. Игровые технологии в образовательном процессе // Проблемы университетского образования. Компетентностный подход к образованию: сборник статей всерос. науч.-метод. конф. Тольятти: ТГУ, 2011. С. 147-151.

13. Гриббин Д. и др. Научные открытия, перевернувшие мир. Как это было. М.: ЗАО «Издательская группа «Контэнт», 2008. 224 с.

14. Струан Рейд, Патриция Фара, Фесили Эверетт. История открытий: Энциклопедия. М.: РОСМЭН,1997. 150 с.

15. Самородский П.С. Основы разработки творческих проектов: книга для учителя. Брянск: Изд-во БГПУ, 1995. $212 \mathrm{c.}$

16. Мигунов В.А., Мельников В.Е., Петряков П.А. Метод проектов в преподавании образовательной области «Технология»: методическое пособие. Великий Новгород: НРЦРО, 1999. 88 с.

17. Кривицкий Б.Х., Скворцов В.В. Презентуем Power Point версии 03: учебное пособие. М.: МГППУ, 2006. $118 \mathrm{c}$.

18. Цыганова Л.В. Использование в образовательном процессе проектной технологии как фактор развития самостоятельности и творческих способностей личности // Самоорганизация личности в современных социокультурных условиях: мат-лы всероссийской науч.-практ. конф. Тольятти: ТГУ, 2007. C. 250-254.

19. Цыганова Л.В. Методика применения стратегий самостоятельной работы при организации и проведении учебных проектов: учебное пособие. Тольятти, Изд-во ТВТИ, 2009. 159 с.

20. Радаев В.В. Как организовать и представить исследовательский проект. 75 простых правил. М.: ВШЭ: ИНФРА-М, 2001. 203 с.

\title{
THEORETICAL AND METHODOLOGICAL FOUNDATIONS OF ORGANIZING STUDENTS' PROJECT ACTIVITY IN INSTITUTIONS OF CHILDREN'S AND YOUTH ARTS
}

(C) 2017

\author{
Mikhelkevich Valentin Nicolaevich, doctor of technical sciences, \\ professor of Psychology and Pedagogy Department \\ Samara State Technical University (Samara, Russian Federation) \\ Ovchinnikova Lyudmila Pavlovna, doctor of pedagogical sciences, \\ professor of Philosophy and History of Science Department \\ Samara State Transport University (Samara, Russian Federation) \\ Lisovskaya Anna Igorevna, director
}

Children's and Youth Arts Center «Raduga Uspekha» of Samara Urban Okrug (Samara, Russian Federation)

\footnotetext{
Abstract. The paper presents theoretical and methodological foundations of students' project activity organization in institutions of children's and youth arts. The retrospective analysis of scientific publications and advanced pedagogical experience related to young people creative development in the system of supplementary education (centers of children's and youth arts et al.) proves that project technology plays a dominant role in encouraging students to learn modeling and design engineering as well as acquiring skills of independent creative activity. Values and advantages of project technology distinguish it favorably from traditional and innovative pedagogical technologies. The paper shows that project technology is oriented to integration, synthesis of students' theoretical knowledge and their practical activity: it means that carrying out a project we not only set a specific creative task but also do our best to put it into practice in the form of pictures, drawings, applications, software, dummies, devices, robots, etc. Undertak-
} 
Михелькевич В.Н., Овчинникова Л.П., Лисовская А.И.

ing a particular project the student is supposed to learn how to identify social and technical contradictions and problems and overcome them. Project technology is focused on students' creative work which helps to develop and strengthen the skills required to organize their independent work. The paper introduces the typology of training projects used in the center of children's and youth arts as well as the techniques of their individual and selective choice. There is a focus on basic classification criteria of training projects: leading modality of students' training and cognitive activity; the levels of interdisciplinary integration of knowledge acquired by the students while carrying out the project; subjects and conditions for project activity organization.

Keywords: theoretical and methodological foundations of organizing project activity; project technology; classification criteria of training projects; students; supplementary education; typology of training projects; practical activity; centers of children's and youth arts.

УДК 378

\title{
СИСТЕМА ФОРМИРОВАНИЯ ГОТОВНОСТИ БУДУЩИХ БАКАЛАВРОВ МАШИНОСТРОЕНИЯ К САМООБРАЗОВАТЕЛЬНОЙ ДЕЯТЕЛЬНОСТИ
}

\author{
(C) 2017 \\ Поднебесова Мария Игоревна, старший преподаватель кафедры информатики и систем управления \\ Филиал Самарского государственного технического университета \\ (2. Сызрань, Самарская область, Российская Федеращия)
}

\begin{abstract}
Аннотащия. В статье рассматривается проблема профессиональной подготовки бакалавров машиностроения в техническом вузе. Доказывается актуальность формирования у будущих специалистов способностей к самообразованию. Предложена эффективная система формирования готовности будущих бакалавров машиностроения к самообразовательной деятельности средствами информационных и коммуникационных технологий и активных методов обучения дисциплине «Информатика» с внедренным спецкомпонентом, способствующим развитию показателей в структуре готовности. Система формирования готовности будущих бакалавров машиностроения к самообразовательной деятельности представляется разновидностью педагогической системы, включающей в себя методологический, содержательный, процессуальный и результативный элементы. Основополагающими при разработке системы являются принципы системно-структурного, деятельностного, акмеологического и компетентностного подходов, позволяющие спроектировать элементы системы и выбрать средства формирования готовности адекватно ее целям. Выбор дисциплины «Информатика» в качестве средства формирования готовности обусловлен выделенной в процессе исследования спецификой профессиональной деятельности бакалавров машиностроения. Обосновывается необходимость применения активных и интерактивных методов обучения, а также информационных и коммуникационных технологий для повышения эффективности формирования готовности будущих бакалавров машиностроения к самообразовательной деятельности. Полученные материалы могут служить основой для организации учебной деятельности студентов и дальнейшего мониторинга качества их профессиональной подготовки.

Ключевые слова: бакалавр машиностроения; готовность к самообразовательной деятельности; системноструктурный, деятельностный и акмеологический подходы; система формирования готовности будущих бакалавров машиностроения к самообразовательной деятельности; акмеологические технологии; активные методы обучения.
\end{abstract}

Развитие машиностроения как базовой отрасли промышленности является приоритетной задачей обеспечения высоких темпов роста экономики страны [1]. Модернизация машиностроительного производства, связанная с внедрением инновационных технологий, и происходящие изменения в системе высшего образования актуализируют проблему профессиональной подготовки будущих бакалавров машиностроения в техническом вузе. В то же время социально-экономические преобразования, происходящие в стране в настоящее время, оказывают непосредственное влияние на модернизацию системы образования, предполагающие ее переход от массового к непрерывному индивидуализированному образованию, необходимому для создания инновационной, социально-ориентированной экономики страны [2, c. 14]. Происходит переориентация целей образования на формирование творческой социально ответственной личности. Таким образом, задачей вузов становится подготовка инициативных и самоорганизованных специалистов, способных к самостоятельному приобретению знаний, непрерывному повыше- нию своей профессиональной квалификации, что, в свою очередь, находит отражение в обновленных федеральных государственных образовательных стандартах в виде соответствующих компетенций.

В результате анализа Федерального государственного образовательного стандарта высшего профессионального образования (ФГОС ВО) по направлению подготовки 15.03.05 Конструкторско-технологическое обеспечение машиностроительных производств (уровень бакалавриата) [3] было обнаружено, что среди общекультурных, общепрофессиональных и профессиональных компетенций, сформированность которых является показателем результата освоения образовательной программы, выделяются компетенции, отражающие готовность выпускника к самообразовательной деятельности. Результаты исследования, проведенного среди студентов Сызранского филиала Самарского государственного технического университета (анкетирование студентов, обучающихся по профилю «Технология машиностроения» - выборка 128 человек) позволили сделать вывод о том, что в целом способности к самообразо- 